\title{
POSSIBILIDADES DE INTERAÇÃO E TROCA DE EXPERIÊNCIAS ENTRE PÓS-GRADUANDOS E GRADUANDOS EM UM PROJETO DE EXTENSÃO EM ODONTOLOGIA
}

\author{
Eduardo Bauml Campagnoli \\ Universidade Estadual de Ponta Grossa \\ ebcampagnoli@uepg.br \\ Karina Regalio Campagnoli \\ Universidade Estadual de Ponta Grossa \\ karinaregalio@hotmail.com
}

Resumo

O objetivo deste artigo é refletir sobre algumas possibilidades de interação e de troca de experiências entre pós-graduandos e graduandos que participaram de um projeto de extensão na área de Odontologia nos anos de 2018 e 2019. Para isso, são problematizadas algumas ações realizadas por esses dois grupos de estudantes em uma comunidade rural do município de Ponta Grossa - Paraná, a partir da compreensão de aprendizagem colaborativa, conforme preconizado por Paulo Freire. Compreende-se que as atividades de extensão realizadas apresentaram o potencial de motivar os alunos para a aprendizagem dos conteúdos específicos, articulando a teoria com a prática, transcendendo os conhecimentos técnicos. Dessa forma, também buscou-se abranger os aspectos éticos, políticos, sociais, abarcando, assim, uma formação integral, alinhada com as necessidades da comunidade em questão.

Palavras-chave: Extensão Universitária. Odontologia. Educação em Saúde.

\section{POSSIBILITIES FOR INTERACTION AND EXCHANGE OF EXPERIENCES BETWEEN GRADUATE AND UNDERGRADUATE STUDENTS IN AN EXTENSION PROJECT IN ODONTOLOGY}

\begin{abstract}
The purpose of this article is to reflect on some possibilities of interaction and exchange of experiences between graduate students and undergraduate students who participated in an extension project in the area of Odontology, in the years 2018 and 2019. For this, some actions carried out are problematized by these two groups of students in a rural community of Ponta Grossa - Paraná - Brazil. Based on the understanding of collaborative learning, as recommended by Paulo Freire. It is understood that the extension activities carried out, had the potential to motivate students to learn specific content, articulating theory with practice, going beyond technical knowledge. In this way, we also sought to cover ethical, political, and social aspects, thus encompassing comprehensive training, aligned with the needs of the community.

Keywords: University Extension. Odontology. Health Education.

\section{POSIBILIDADES DE INTERACCIÓN E INTERCAMBIO DE EXPERIENCIAS ENTRE ESTUDIANTES DE POSGRADO Y PREGRADO EN UN PROYECTO DE EXTENSIÓN EN ODONTOLOGÍA}

Resumen

El propósito de este artículo es reflexionar sobre algunas posibilidades de interacción e intercambio de experiencias entre estudiantes de posgrado y estudiantes de pregrado que participaron en un proyecto de extensión en el área de Odontología en los años 2018 y 2019. Para ello, se problematizan algunas acciones realizadas. por estos dos grupos de estudiantes de una comunidad rural del municipio de Ponta Grossa - Paraná - Brasil, a partir de la comprensión del aprendizaje colaborativo, como recomienda Paulo Freire. Se entiende que las actividades de extensión realizadas, tuvieron el potencial de motivar a los estudiantes a aprender contenidos específicos, articulando la teoría con la práctica, yendo más allá de los conocimientos técnicos. De esta manera, también buscamos cubrir aspectos éticos, políticos y sociales, abarcando así una formación integral, alineada con las necesidades de la comunidad en cuestión.

Palabras clave: Extensión Universitaria. Odontología. Educación para la Salud. 
Possibilidades de interação e troca de experiências entre pós-graduandos e graduandos em um projeto de extensão em Odontologia

\section{INTRODUÇÃO}

O objetivo deste artigo é refletir sobre as articulações e as possibilidades de formação, tanto acadêmica, como profissional, pessoal e humana, a partir das experiências de um projeto de extensão intitulado "Atuação dos pós-graduandos de Odontologia (Lato sensu, Stricto sensu e Residências), no Programa Centro Rural de Treinamento e Ação Comunitária - CRUTAC”, projeto esse que envolveu alunos de Pós-Graduação e de Graduação em Odontologia, ambas modalidades de ensino da Universidade Estadual de Ponta Grossa (UEPG).

Assim, a partir da compreensão da relevância da articulação entre ensino, pesquisa e extensão, como o tríplice alicerce que sustenta e justifica as atividades de uma universidade, conforme consta no documento do Fórum de Pró-Reitores de Extensão das Universidades Públicas Brasileiras (Forproex) (2012), este artigo procura debater o papel da extensão enquanto oportunidade de aquisição de novas vivências e de aprendizados para pós-graduandos e graduandos, por meio do contato com a comunidade, transpassando os muros institucionais.

As ações que compõem este projeto extensionista foram realizadas em uma comunidade rural da cidade de Ponta Grossa - Paraná (PR), distante cerca de 33 quilômetros do centro da cidade, a partir do contato com os pacientes que frequentaram a Unidade Básica de Saúde (UBS) e uma escola municipal da região, entre os anos de 2018 e 2019.

Dessa forma, seguindo as orientações expressas na Resolução $n^{\circ}$ 7, de 18 de dezembro de 2018, que estabelece as Diretrizes para a Extensão na Educação Superior Brasileira, fica registrado no artigo $3^{\circ}$ que:

\footnotetext{
A Extensão na Educação Superior Brasileira é a atividade que se integra à matriz curricular e à organização da pesquisa, constituindo-se em processo interdisciplinar, político educacional, cultural, científico, tecnológico, que promove a interação transformadora entre as instituições de ensino superior e os outros setores da sociedade, por meio da produção e da aplicação do conhecimento, em articulação permanente com o ensino e a pesquisa.
}

Nesse sentido, procurou-se seguir o exposto no excerto acima e também atentou-se para o que aponta o artigo $5^{\circ}$ da mesma resolução, que especifica, no inciso I, a relevância da "interação dialógica da comunidade acadêmica com a sociedade, por meio da troca de conhecimentos, da participação e do contato com as questões complexas contemporâneas presentes no contexto social". Além disso, ainda no artigo $5^{\circ}$, encontra-se explícito o enfoque no investimento para "a formação cidadã dos estudantes, marcada e constituída pela vivência dos seus conhecimentos, que, de modo interprofissional e interdisciplinar, seja valorizada e integrada à matriz curricular”. Outro ponto fundamental deste artigo ressalta "a articulação entre ensino/extensão/pesquisa, ancorada em processo pedagógico único, interdisciplinar, político educacional, cultural, científico e 
Possibilidades de interação e troca de experiências entre pós-graduandos e graduandos em um projeto de extensão em Odontologia

tecnológico", orientação essa que também foi observada durante o planejamento e consolidação das atividades deste projeto de extensão, conforme será apresentado mais adiante.

Essa resolução ainda norteia as ações e possíveis estratégias extensionistas, elucidadas, no artigo $6^{\circ}$, inciso I, como "a contribuição na formação integral do estudante, estimulando sua formação como cidadão crítico e responsável". Ainda nesse mesmo artigo, outro ponto importante nessa análise diz respeito aos aspectos éticos, previsto no inciso IV, que enfatiza que as atividades extensionistas podem favorecer "a promoção da reflexão ética quanto à dimensão social do ensino e da pesquisa". Além disso, no inciso V ressalta-se “o incentivo à atuação da comunidade acadêmica e técnica na contribuição ao enfrentamento das questões da sociedade brasileira, inclusive por meio do desenvolvimento econômico, social e cultural”. Outra normativa importante consta no inciso VII, o qual salienta "a atuação na produção e na construção de conhecimentos, atualizados e coerentes, voltados para o desenvolvimento social, equitativo, sustentável, com a realidade brasileira".

Assim sendo, a partir da citação dos principais artigos e incisos da Resolução $n^{\circ} 7$, a qual norteia as atividades extensionistas realizadas no Ensino Superior do Brasil desde 2018, enfatiza-se o compromisso que este projeto de extensão procurou ter ao seguir estas orientações, buscando alinhar-se aos preceitos que dizem respeito à formação integral dos estudantes, assim como à observação aos aspectos éticos e morais, além do cuidado e atenção com a comunidade com a qual se manteve interação durante o período de realização das atividades que serão descritas adiante.

Nesse sentido, este artigo caracteriza-se como relato de experiência e para fundamentar teoricamente as atividades extensionistas aqui relatadas, optou-se pelas contribuições de Paulo Freire (2014; 2015); Zanon; Althaus e Bagio (2018); Fujita e Barraviera (2014); Gadotti (2017), entre outros. Além disso, os relatos de alguns pós-graduandos e acadêmicos, obtidos a partir das avaliações discentes realizadas ao fim de cada semestre de vigência deste projeto de extensão, também foram utilizados para subsidiar os expostos ao longo deste artigo. Ressalta-se que a identidade dos alunos foi mantida em sigilo, sendo seus relatos designados por letras, como: A para acadêmicos, $\mathrm{M}$ para mestrandos, $\mathrm{D}$ para doutorandos e $\mathrm{R}$ para residentes, seguidos por números, para manter o anonimato.

\section{ASPECTOS TEÓRICOS}

A abordagem teórica que sustenta este artigo pauta-se na valorização dos conhecimentos compartilhados entre os vários atores que compõem a sociedade, conforme defendido por Paulo Freire (2014). Aqui, no caso, essas trocas de experiências foram personificadas pelos pós- 
Possibilidades de interação e troca de experiências entre pós-graduandos e graduandos em um projeto de extensão em Odontologia

graduandos de cursos relacionados à área odontológica e os acadêmicos do curso de Odontologia, sendo essas duas modalidades de ensino - Pós-Graduação e Graduação - vinculadas à UEPG, em interação com a comunidade usuária de uma UBS, da zona rural de Ponta Grossa - PR.

Nesse sentido, defende-se aqui que essa horizontalidade das relações, proposta por Freire (2014; 2015), pode favorecer a aprendizagem e a formação dos indivíduos, não somente no sentido técnico e profissional, mas também na observação e desenvolvimento de uma formação humanizada e atenta às necessidades sociais da população. Assim, parte-se do princípio de que “[...] ensinar não é transferir conhecimento, mas criar as possibilidades para a sua própria produção ou a sua construção" (FREIRE, 2015, p. 47). Dessa forma,

\begin{abstract}
A Extensão é uma via de mão dupla, com trânsito assegurado à comunidade acadêmica, que encontrará, na sociedade, a oportunidade de elaboração da práxis de um conhecimento acadêmico. No retorno à Universidade, docentes e discentes trarão um aprendizado que, submetido à reflexão teórica, será acrescido àquele conhecimento. (FUJITA; BARRAVIERA, 2014, p.3).
\end{abstract}

Seguindo por essa ótica, a resposta de uma doutoranda, designada como D1, corrobora o que foi exposto acima, pois, segundo ela: "Com o projeto, pude me relacionar com pacientes fora da área acadêmica. Conheci coisas diferentes e pude compartilhar com outros colegas. Aprendi e pratiquei os conhecimentos aprendidos na teoria".

Desse modo, de acordo com Barja-Fidalgo et al. (2014, p. 93), “a Extensão deve ser vista [...] como aproximação, integração e parceria da academia com a sociedade, [...] de acordo com a realidade e as necessidades específicas da sociedade, o que é de suma importância para a formação profissional". Sobre isso, torna-se importante discutir o papel social da universidade, enquanto espaço de formação humana, enfatizando a realização das atividades extensionistas como oportunidades para esse desenvolvimento. Sobre isso, outra doutoranda, designada como D2, escreveu que "[...] o projeto trata o paciente como um todo, pois aqui também podemos finalizar os tratamentos $[. .$.$] ", portanto, superando a tradicional abordagem restrita somente à região da$ boca. Assim, é interessante esclarecer que:

\footnotetext{
A universidade brasileira nasceu, tardiamente, na primeira metade do século XX e foi só a partir dos anos 1950 e 1960 que ela despertou para o seu compromisso social, muito por influência dos movimentos sociais, particularmente, com a participação da União Nacional dos Estudantes (UNE) com seu projeto UNE Volante, que previa uma mobilização nacional a partir de caravanas. Destaque-se, nesse período, o trabalho de Paulo Freire, criando o Serviço de Extensão Cultural, na Universidade do Recife, bem como o Movimento de Cultural Popular [...], o Movimento de Educação de Base [...] e o Centro Popular de Cultura [...] da UNE. (GADOTTI, 2017, p. 1).
}

Gadotti (2017), no excerto anterior, destaca a postura engajada de Paulo Freire e dos estudantes em atividades de extensão, defendendo a concepção de que todos podem aprender uns com os outros e em relações de reciprocidade, confirmando, assim, a postura também assumida 
Possibilidades de interação e troca de experiências entre pós-graduandos e graduandos em um projeto de extensão em Odontologia

neste artigo. Nesse sentido, Pereira et al. (2011, p. 95-96) explicam alguns dos pontos positivos proporcionados pelas atividades extensionistas, reiterando que:

[...] verifica-se que a extensão universitária e o serviço voluntário são importantes meios facilitadores de interações mais dinâmicas e verdadeiras entre o aluno e a comunidade, sendo que os frutos dessa interação beneficiam a ambos. O aluno, portanto, ao se confrontar com a realidade da população, a qual geralmente apresenta características socioeconômicas e culturais bem diferentes das encontradas no seu grupo social, obrigao a buscar conhecimentos muitas vezes não contemplados nos assentos universitários [...]. (PEREIRA et al., 2011, p. 95-96).

Nesse sentido, ao problematizar o papel social da universidade e suas limitações na busca por novos conhecimentos, refletindo sobre as possibilidades de uma formação consciente das responsabilidades advindas com um título acadêmico, Pivetta et al. (2010, p. 378) justificam que:

Entre os diferentes espaços de construção do conhecimento, a universidade ocupa um lugar privilegiado de convivência e desenvolvimento humano, científico-tecnológico e social. Tem como eixo central a formação de profissionais-cidadãos, isto é, de profissionais comprometidos com o desenvolvimento social em nível local e global.

Dessa forma, ao compreender a relevância dos 3 pilares que compõem a universidade, a saber: ensino, pesquisa e extensão (FORPROEX, 2012), sem escalas hierárquicas entre eles e em similitude de importância no processo formativo de pós-graduandos e acadêmicos, Gadotti (2017, p. 9), ao analisar o desenvolvimento histórico das ações extensionistas no Brasil, aponta que:

\footnotetext{
O princípio da integralidade é fundamental na Extensão Universitária. É preciso conectar as três funções da universidade para que a educação seja integral. O currículo não é a soma de um conjunto de disciplinas. Ele traduz um projeto político pedagógico integrado. Por isso, um dos principais desafios da curricularização da Extensão está na superação de uma prática fragmentada de pequenos projetos por uma prática integral e integradora. (GADOTTI, 2017, p. 9).
}

Freire (2015, p. 30-31) também discute as interrelações entre o ensino, a pesquisa e a extensão, ressaltando que essas 3 esferas estão em relacionamento próximo, devendo ser compreendidas de modo a uma complementar a outra, uma vez que:

\footnotetext{
Não há ensino sem pesquisa e pesquisa sem ensino. Esses fazeres se encontram um no corpo do outro. Enquanto ensino continuo buscando, reprocurando. Ensino porque busco, porque indaguei, porque indago e me indago. Pesquiso para constatar, constatando, intervenho, intervindo educo e me educo. Pesquiso para conhecer o que ainda não conheço e comunicar ou anunciar a novidade.
}

Sobre essa interessante articulação entre ensino, pesquisa e extensão, especialmente do ponto de vista de aquisição de conhecimentos de forma significativa para todos os envolvidos nesse processo de aprendizagem, Zanon; Althaus e Bagio (2018, p. 76) enfatizam que "A pesquisa no ensino é uma das estratégias mais eficientes para a promoção do conhecimento, pois propicia o 
Possibilidades de interação e troca de experiências entre pós-graduandos e graduandos em um projeto de extensão em Odontologia

desenvolvimento do raciocínio crítico". Especificamente sobre a extensão, espaço de atuação bastante problematizado por Freire em suas pesquisas, uma vez que a trajetória desse educador demonstra seu apreço pela aproximação e pela valorização dos conhecimentos das comunidades ponto-chave da extensão - Freire (2014, p. 96) ressalta que “[...] ninguém educa ninguém, como tampouco ninguém se educa a si mesmo: os homens se educam em comunhão, mediatizados pelo mundo".

Assim sendo, as ações de extensão podem ser bem-vindas, especialmente se forem consideradas, no sentido de que:

\begin{abstract}
As estratégias de ensino vinculadas à tríade ensino, pesquisa e extensão possibilitam a geração de novos conhecimentos, por meio de pesquisas desenvolvidas, do aprimoramento técnico-científico da equipe participante e do fortalecimento do vínculo entre os três eixos norteadores da tríade. (MOIMAZ et al., 2015, p. 146).
\end{abstract}

O exposto no excerto anterior complementa a função da universidade, indicada por Garcia (2012, p. 41), tornando apropriadas as considerações da autora, uma vez que:

\begin{abstract}
Sabe-se que a universidade nasceu para cumprir o papel primeiro que é o de ensinar, de preparar profissionais para a sociedade para que exerçam sua profissão, seja ela qual for, todavia se acreditamos que devemos ir para além da técnica, na direção do compromisso social, precisamos fazer bom uso das atividades acadêmicas para que essas acrescentem algo para dar sentido a uma prática, entendida para além do caráter utilitário, na direção da práxis. (itálico da autora).
\end{abstract}

Nesse sentido, as observações em relação às articulações entre ensino, pesquisa e extensão sustentam que as atividades extensionistas podem ser compreendidas como uma forma de aprendizado, pois permitem a interação com os demais colegas, além do contato com a comunidade, numa interessante troca de experiências e vivências (FREIRE, 2014; 2015). No entanto, Borato et al. (2018, p. 104) ainda destacam que:

\footnotetext{
Assumiu-se que, apesar do princípio da indissociabilidade entre ensino, pesquisa e extensão ter sido configurado no cenário da educação superior brasileira há quase trinta anos, ainda é um tema complexo e discutido por vários autores. Além disso, considerouse que a formação do profissional da Área da Saúde vem sendo problematizada à luz do SUS [Sistema Único de Saúde], a qual exige que os profissionais se tornem mais comprometidos com a igualdade na saúde, ampliando a dimensão de cuidado na prática profissional. (BORATO et al., 2018, p. 104).
}

Assim, especificamente sobre as ações direcionadas para a área da saúde, é importante problematizar as observações realizadas por Pereira et al. (2011, p. 96), ao apontarem as fragilidades do enfoque dado, em alguns casos, às questões técnicas dos cursos, em detrimento de um desenvolvimento humano, a partir da aquisição de conhecimentos com cunho social e político. Sobre isso, os autores alegam que: 
Possibilidades de interação e troca de experiências entre pós-graduandos e graduandos em um projeto de extensão em Odontologia

Embora todos concordem, de maneira geral, quanto à importância da educação na solução de problemas de saúde bucal, não causa surpresa a verificação de que os profissionais da área da saúde não compreendem a importância do processo educativo, visto que a maioria recebeu treinamento e experiência em ciências médicas e biológicas, enquanto que o processo educativo tem por base as ciências sociais. (PEREIRA et al., 2011, p. 96)

Seguindo essa perspectiva, Pereira et al. (2011, p. 100) ainda apontam que "[as universidades ao] proporcionarem a seus alunos um ensino integral, onde prática e teoria andam juntas, desenvolvem também habilidades de comunicação, bastante exigidas na prática com a comunidade e frente a seus futuros pacientes". Ademais, segundo os autores, "além dos benefícios à formação do profissional, o incentivo à prática de serviços voluntários sociais, proporciona oportunidade à população carente de receber informações valiosas à sua saúde de forma gratuita e de qualidade" (PEREIRA et al., 2011, p. 97).

Nesse ponto é importante enfatizar novamente o que Freire (2014; 2015) indica, no sentido de que todos possuem conhecimentos e que o processo educativo deve ser compreendido como uma troca, uma vez que tanto o educando, quanto o educador, assim como a comunidade envolvida, podem se beneficiar dos conhecimentos adquiridos. Assim, é importante reforçar a postura de que a universidade, representada aqui pelos pós-graduandos, acadêmicos e professor supervisor, sempre evitou se posicionar como detentora do saber, mas, sim, partiu-se da concepção de que é interessante estimular a autonomia dos indivíduos e a expressão de suas contribuições por meio do diálogo, compreendendo que todos se encontram em constante aprendizado e aperfeiçoamento durante as atividades extensionistas, favorecidos pelo contato com a comunidade. Sobre essa importante discussão, Freire (2015, p. 113) explica que:

\footnotetext{
A desconsideração total pela formação integral do ser humano e sua redução a puro treino fortalecem a maneira autoritária de falar de cima para baixo. Nesse caso, falar a, que na perspectiva democrática é um possível momento do falar com, nem sequer é ensaiado. A desconsideração total pela formação integral do ser humano, a sua redução a puro treino, fortalecem a maneira autoritária de falar de cima para baixo, a que falta, por isso mesmo, a intenção de sua democratização no falar com.
}

Nesse sentido, torna-se pertinente reforçar que o conceito de "educação bancária" cunhado por Freire (2014), caracterizado por um sistema educativo, no qual somente o professor tem direito à palavra e em que os alunos são passivos e distantes da realidade do dia a dia - já não basta para desenvolver nos alunos uma consciência crítica sobre sua profissão. Assim, mostra-se fundamental, portanto, apresentar e desenvolver uma abordagem, chamada pelo autor de “educação problematizadora”, a qual parte da realidade observada, ou então, dos problemas sociais sofridos pelas comunidades assistidas e que necessitam de auxílio imediato, conforme também 
Possibilidades de interação e troca de experiências entre pós-graduandos e graduandos em um projeto de extensão em Odontologia

apontado pelas autoras Zanon; Althaus e Bagio (2018). Dessa forma, mostra-se pertinente a discussão travada por Borato et al. (2018, p. 113), na qual os autores afirmam que:

\begin{abstract}
Sem dúvida, a indissociabilidade se relaciona intimamente à qualidade da produção e à socialização do conhecimento na educação superior, ao incorporar nos acadêmicos mecanismos de reflexão social e crítica, de emancipação teórica e prática. Assim, as [Instituições de Ensino Superior] IES brasileiras deparam-se com desafios comuns a serem superados, pois, se por um lado existem políticas que estimulam uma espécie de atitude reativa por parte da comunidade universitária, por outro, permanecem as dificuldades de institucionalização dessas novas práticas. (BORATO et al., 2018, p. 113).
\end{abstract}

Assim sendo, partindo da premissa de que os pós-graduandos, acadêmicos, comunidade e demais atores envolvidos nesse projeto de extensão puderam se beneficiar, a partir dos conhecimentos adquiridos em conjunto, no próximo tópico serão apresentados os detalhes e demais elementos que compuseram o projeto de extensão aqui descrito.

\title{
Apresentando o Projeto de Extensão: “Atuação dos pós-graduandos de Odontologia (Lato sensu, Stricto sensu e Residências) no Programa Centro Rural de Treinamento e Ação Comunitária - CRUTAC"
}

O projeto de extensão intitulado "Atuação dos pós-graduandos de Odontologia (Lato senso, Stricto senso e Residências), no Programa Centro Rural de Treinamento e Ação Comunitária - CRUTAC", é coordenado por professores supervisores pertencentes ao Departamento de Odontologia da UEPG. Ele foi composto por mestrandos e doutorandos do Programa de PósGraduação Stricto sensu em Odontologia, do Programa de Residência Multiprofissional em Saúde do Idoso, Programa de Residência Multiprofissional em Intensivismo e Programa de Residência Multiprofissional em Neonatologia, sendo esses três programas de Pós-Graduação vinculados ao Hospital Universitário Regional de Ponta Grossa. Além disso, este projeto extensionista também contou com a participação de acadêmicos do $2^{\circ}$ ano do Curso de Odontologia da UEPG, apesar de o foco inicial deste projeto concentrar-se na participação de pós-graduandos.

Sobre isso, é importante esclarecer que, mesmo que à princípio, o envolvimento de graduandos não era o foco principal, o interesse espontâneo de alguns desses graduandos em participar das ações realizadas pelo projeto motivou a inserção de um número maior de acadêmicos, situação essa que se mostrou muito proveitosa e interessante para o compartilhamento de saberes e vivências entre graduandos, pós-graduandos e comunidade, encorajando, inclusive, a elaboração deste artigo.

Alguns relatos dos acadêmicos e pós-graduandos, realizados como avaliação discente do projeto de extensão ao final de cada período letivo, trouxeram comentários que demonstraram a aquisição de conhecimentos, não só no sentido técnico, mas também humano. Como exemplo, 
Possibilidades de interação e troca de experiências entre pós-graduandos e graduandos em um projeto de extensão em Odontologia

uma acadêmica, designada como A3, destacou em sua resposta: "Obrigada, professor, pela oportunidade de participar desse projeto. Adorei cada dia e termino o ano muito contente com a profissão que escolhi seguir". Nesse caso específico, percebe-se que as experiências proporcionadas pelo projeto extensionista fizeram com que a acadêmica reafirmasse sua opção profissional pela Odontologia, oportunizando-lhe um contato maior com as vivências cotidianas da prática odontológica.

As atividades realizadas pelos integrantes deste projeto de extensão ocorriam, com frequência de um dia por semana, sempre durante o período da manhã, normalmente compreendendo o espaço de tempo das $8 \mathrm{~h}$ às $13 \mathrm{~h}$. A comunidade rural na qual este projeto se realizou, encontra-se a cerca de 33 quilômetros do centro da cidade de Ponta Grossa - PR. Para se deslocar até lá, os acadêmicos, pós-graduandos e o professor supervisor reuniam-se no campus da UEPG e, com o transporte cedido pela universidade, deslocavam-se até a referida UBS, local em que ocorreram a maior parte das atividades extensionistas deste projeto.

O grupo extensionista foi composto no ano de 2018 por quatro acadêmicos e oito pósgraduandos, sendo que, destes, quatro eram residentes e quatro eram mestrandos ou doutorandos. Os integrantes deste grupo se revezavam a cada semana, a partir da elaboração de uma escala de horários, procurando compor um grupo com cerca de seis a oito participantes. Já no ano de 2019, cinco graduandos fizeram parte das atividades de extensão, juntamente com 14 pós-graduandos, sendo 11 mestrandos ou doutorandos e três residentes.

Essa composição diversificada do referido grupo de extensão foi vista de forma positiva, enquanto propulsora de possibilidades de novas vivências, passíveis de ampla troca de opiniões, impressões e construção de conhecimentos pelos participantes, tanto do ponto de vista dos estudantes, mas também da comunidade envolvida. Sobre isso, Stromberg et al. (2020, p. 7) asseguram que "O trabalho em equipe e a interdisciplinaridade trazem excelentes resultados à comunidade [...], os acadêmicos têm a oportunidade de desenvolver essa habilidade interdisciplinar de trabalhar, melhorando sua capacitação profissional", corroborando, portanto, nossa concepção sobre a extensão na formação acadêmica, ampliando, inclusive, essa ideia para a Pós-Graduação.

Em relação a esses aspectos, uma residente, designada como R1, escreveu em sua avaliação discente que o projeto possibilitava "[...] o acompanhamento de casos clínicos diversos que desenvolvem habilidade prática e aprendizado [e também] a discussão de casos clínicos com outros profissionais habilita para outras situações que, por vezes, estamos desabituados de realizar no dia a dia". Esse relato comprova que o convívio com o grupo de extensão possibilitou a aquisição de novos aprendizados, conforme a própria residente afirmou. 
Possibilidades de interação e troca de experiências entre pós-graduandos e graduandos em um projeto de extensão em Odontologia

Dessa forma, entre os objetivos deste projeto extensionista destaca-se a formação integral dos pós-graduandos (e também dos graduandos) de forma multidisciplinar, ampla e articulada com a realidade social. Para isso, procurou-se levantar os principais problemas e dificuldades da comunidade, quanto à saúde em geral e especificamente à Odontologia, assim como buscou-se estabelecer estratégias que contribuíssem para o aumento da qualidade de vida da população em questão. Além disso, houve a preocupação em estimular a criação de grupos de apoio a pacientes na UBS, os quais podem ser compreendidos como potenciais promotores de saúde, especialmente os relacionados ao chamado HiperDia, que engloba hipertensos e diabéticos, mas também objetivou-se a organização de grupos de gestantes e idosos. Sobre isso, Stromberg et al. (2010, p. 10) argumentam que:

\footnotetext{
A formação pedagógica do aluno não se baseia apenas em conhecimentos teóricos e trabalhos científicos, pois a prática do aprendizado através das extensões tem demonstrado bons resultados na formação dos mesmos. Quando a formação é baseada nas Diretrizes Curriculares Nacionais [...], busca-se transformar o perfil do graduando, o tornando apto a praticar um trabalho multidisciplinar e com atenção aos interesses populacionais.
}

Um ponto muito relevante deste projeto de extensão foi o desenvolvimento de atendimento odontológico clínico, a partir do enfoque nos procedimentos vinculados à chamada atenção primária, a qual deve ser realizada na própria Unidade Básica de Saúde. Além disso, buscouse organizar um fluxograma de encaminhamento de pacientes para a atenção secundária e terciária, indicadas para casos que extrapolassem os limites e condições da UBS. Por fim, contemplou-se a articulação das atividades extensionistas junto à pesquisa e o ensino, compondo, assim, os pilares da universidade.

Em relação aos pacientes atendidos, os relatos dos alunos também expressaram as boas relações que foram desenvolvidas ao longo do decorrer do projeto de extensão, como a acadêmica designada como A3, a qual escreveu que o projeto de extensão "beneficia a população, levando saúde bucal a comunidades distantes dos centros urbanos e da universidade. É um direito de todos, independente da localização". A acadêmica designada como A1 também expressou suas opiniões de forma similar, alegando que a presença do projeto de extensão foi de "[...] de extrema importância, pois atende pacientes que não têm como ser atendidos em outro lugar e que realmente precisam de atendimento". A mestranda designada como M1 também se manifestou nesse sentido, escrevendo que: “O principal benefício aos pacientes é o acesso à assistência odontológica, englobando prevenção e tratamento odontológico. São pessoas que ficam à margem dos cuidados em saúde, e que provavelmente não estariam recebendo assistência, sem a presença constante da instituição [UEPG]”. 
Possibilidades de interação e troca de experiências entre pós-graduandos e graduandos em um projeto de extensão em Odontologia

Sobre essa oportunidade de atendimento odontológico a pacientes fora do ambiente universitário, uma mestranda que fez parte do grupo extensionista escreveu em sua avaliação semestral sobre os pontos positivos que ela percebeu sobre isso. Segundo a mestranda, designada aqui como M1: "O Stricto sensu distancia as atividades práticas e comunitárias, assim o projeto garante que se mantenha um vínculo com a assistência odontológica (procedimentos clínicos, prescrição medicamentosa, solicitação de exames e trabalho em equipe)". Já uma acadêmica do $2^{\circ}$ ano do curso de Odontologia, portanto, ainda no início da graduação, designada como A2, descreve assim sua experiência prática de atendimentos odontológicos a pacientes: "Como estou no $2^{\circ}$ ano da graduação, a aplicação na prática dos conteúdos aprendidos nas aulas teóricas é de grande valia. [...] e tenho a oportunidade de aprender coisas novas também". Outra acadêmica, também do $2^{\circ}$ ano de graduação, designada como A1 escreveu: "A maior parte do meu contato com pacientes até agora foi aqui [em ações extensionistas]. Adquiri prática aqui e acho que entrei em contato com pacientes que não entraria se ficasse só na UEPG".

Todos esses relatos demonstram que o referido projeto de extensão conseguiu cumprir com suas metas, proporcionando oportunidades para que os alunos, tanto da graduação, quanto da pós-graduação, refletissem sobre suas práticas, problematizassem as condições de saúde bucal no Brasil e interagissem de forma a avançar na construção do conhecimento, atendendo às necessidades da população e promovendo saúde de forma integral.

Dentre as ações que foram vinculadas ao referido projeto de extensão, algumas foram realizadas na UBS já citada, destacando-se o atendimento odontológico aos pacientes e orientação de higiene bucal, englobando diversos grupos de indivíduos assistidos, especialmente idosos, crianças, gestantes e alguns pacientes com comprometimento sistêmico, como diabetes, hipertensão arterial, distúrbios neurológicos, entre outros. Importante salientar que as ações do grupo extensionista não se restringiam apenas a atendimentos na Unidade Básica de Saúde, mas também a ações de orientação de higiene bucal que foram realizadas em uma escola pública nas proximidades da referida UBS. Dentre essas ações educativas, em uma oportunidade, os pósgraduandos e graduandos realizaram uma dramatização para alunos da Educação Infantil, com idades entre 4 e 5 anos, a partir da encenação de uma peça de teatro em que os próprios estudantes atuavam, salientando os cuidados para se evitar as principais doenças bucais de forma lúdica. Os feedbacks para atividades como essa sempre foram bastante positivos, oportunizando, em várias ocasiões, o contato dos pós-graduandos e acadêmicos com a parcela infantil que compunha essa comunidade.

No ano de 2018, os componentes do grupo extensionista prestaram atendimento odontológico a 20 crianças e 8 adultos, considerando-se que o referido projeto iniciou suas 
Possibilidades de interação e troca de experiências entre pós-graduandos e graduandos em um projeto de extensão em Odontologia

atividades na UBS no mês de novembro. Já no ano de 2019, foram realizados 58 atendimentos a pacientes provenientes do distrito conhecido como Cerrado Grande e 14 atendimentos odontológicos à população da região de Carazinho, ambos pertencentes à área de abrangência da UBS correspondente. Como benefício extra para a comunidade, destaca-se o atendimento semanal oportunizado aos pacientes pertencentes à UBS em questão, realizado pelo grupo de estudantes já mencionados, ampliando, assim, o número de consultas, orientações e procedimentos clínicos que antes ocorriam em menor número, levando-se em consideração que a referida UBS não dispunha de profissionais de saúde da área da Odontologia para atendimento em todos os dias da semana. É importante salientar que outras atividades de prevenção de saúde, como palestras, abordagens sobre cuidados com a saúde em geral e orientações de higiene bucal foram realizados de modo contínuo, não sendo, portanto, contabilizados. No entanto, entende-se que o fato de essas ações não serem computadas como atendimentos odontológicos clínicos, não diminuem sua relevância em termos de promoção e manutenção de saúde à comunidade atendida.

Em relação às limitações e dificuldades enfrentadas no desenvolvimento do projeto de extensão aqui relatado, salientam-se a distância e o tempo gasto para se deslocar da UEPG à UBS, uma vez que esta se encontra na zona rural, dificultando o acesso dos pós-graduandos, graduandos e professores supervisores, necessitando, assim, dos meios de transporte oficiais da UEPG para esse deslocamento. Além disso, foi necessária uma articulação com a equipe de funcionários que já atuava na UBS, para que a concretização do projeto de extensão se tornasse viável. Possivelmente, em futuras edições deste projeto extensionista, uma vez que já foi estabelecido o vínculo inicial com a comunidade e também com a equipe de saúde que atua na UBS, novas possibilidades de atuação poderão se desenvolver, abarcando ações educativas e preventivas voltadas para a saúde, em articulação com os atendimentos clínicos.

\section{CONSIDERAÇÕES FINAIS}

O objetivo deste artigo foi apresentar subsídios que possibilitassem reflexões sobre as possíveis trocas de experiências, vivências e conhecimentos entre a pós-graduação, a graduação e a comunidade, por meio de atividades desenvolvidas por um projeto de extensão vinculado à área da Odontologia, intitulado "Atuação dos pós-graduandos de Odontologia (Lato senso, Stricto senso e Residências), no Programa Centro Rural de Treinamento e Ação Comunitária CRUTAC", e coordenado por professores pertencentes ao Departamento de Odontologia da Universidade Estadual de Ponta Grossa (UEPG). 
Possibilidades de interação e troca de experiências entre pós-graduandos e graduandos em um projeto de extensão em Odontologia

Dessa forma, a partir deste artigo, elaborado como um relato de experiência, compreendese que é possível articular ações extensionistas que envolvam a comunidade, no caso aqui, indivíduos pertencentes a uma área rural do município de Ponta Grossa - PR, representados por pacientes que frequentavam a Unidade Básica de Saúde (UBS) e crianças de uma escola pública de Educação Infantil e Anos Iniciais do Ensino Fundamental da referida região em questão, distante cerca de 30 quilômetros do centro da cidade.

Nesse sentido, contando com o aporte teórico pautado nos preceitos de Paulo Freire (2014; 2015), autor que defende a horizontalidade das relações, o compartilhamento das ideias e impressões, a postura autônoma e ativa dos atores envolvidos nos processos de construção dos conhecimentos, depreende-se que o projeto de extensão aqui descrito cumpriu com seus principais objetivos, favorecendo o desenvolvimento integral dos estudantes envolvidos nas atividades extensionistas, além de proporcionar ações que privilegiaram a prevenção e a manutenção da saúde bucal e geral da comunidade envolvida.

Dessa forma, reitera-se o compromisso da universidade, alicerçada pelo tripé que abarca o ensino, a pesquisa e a extensão de modo integrado e harmonioso, não elegendo qualquer uma dessas esferas como a mais relevante, mas, sim, compreendendo que todas devem estar alinhadas no sentido de uma formação humana, ética, social e política dos estudantes, procurando também envolver-se com a comunidade.

Assim sendo, neste artigo relatou-se a ideia de um projeto de extensão que, originalmente, previa apenas a participação de pós-graduandos nas atividades propostas, mas que, ao longo de sua concretização, deparou-se com a solicitação de acadêmicos que demonstraram interesse em também participar destas ações. Com isso, constata-se que as atividades extensionistas podem se apresentar como possibilidades múltiplas de aprendizagens para todos os atores envolvidos nesse processo, a partir do olhar atento e da concepção de que todos podem aprender e avançar de modo conjunto.

\section{REFERÊNCIAS}

BARJA-FIDALGO, F. et al. Projeto de extensão Crescer Sorrindo: integrando ensino, pesquisa e extensão em Odontologia por 12 anos crescer sorrindo. Revista Conexão, Ponta Grossa, v. 10, n. 1, p. 92-101, jan./jun. 2014.

BORATO, A. et al. Valoração das práticas de ensino, pesquisa e extensão entre concluintes de Odontologia. Revista da ABENO, Londrina, v. 18, n. 1, p. 103-115, 2018.

BRASIL. Ministério da Educação. Conselho Nacional de Educação. Câmara de Educação Superior. Resolução $\mathbf{n}^{\mathbf{0}}$ 7, de 18 de dezembro de 2018. Estabelece as Diretrizes para a Extensão na 
Possibilidades de interação e troca de experiências entre pós-graduandos e graduandos em um projeto de extensão em Odontologia

Educação Superior Brasileira e regimenta o disposto na Meta 12.7 da Lei ${ }^{\circ}$ 13.005/2014, que aprova o Plano Nacional de Educação - PNE 2014-2024 e dá outras providências. Brasília.

FÓRUM DE PRÓ-REITORES DE EXTENSÃO DAS INSTITUIÇÕES DE EDUCAÇÃO SUPERIOR PÚBLICA BRASILEIRAS. Manaus, maio, 2012. Disponível em: http://www.utfpr.edu.br/estrutura-universitaria/pro-reitorias/prorec/diretoria-deextensao/documentos-da-extensao-de-ambito-nacional/politica-nacional-de-extensaouniversitaria-forproex-2012/view. Acesso em: 20 jul. 2020.

FREIRE, P. Pedagogia do oprimido. 58 ed. Rio de Janeiro: Paz e Terra, 2014.

FREIRE, P. Pedagogia da autonomia: saberes necessários à prática educativa. 50 ed. Rio de Janeiro: Paz e Terra, 2015.

FUJITA, M. S. L.; BARRAVIERA, B. Revista Ciência Em Extensão: 10 anos disseminando conhecimento e transformando a relação entre a Universidade e a Sociedade. Editorial. Rev. Ciênc. Ext. v.10, n.3, p.2-4, 2014.

GARCIA, B. R. Z. A contribuição da extensão universitária para a formação docente. 2012. 115 f. Tese (Doutorado em Educação) - Psicologia da Educação, Pontifícia Universidade Católica de São Paulo, São Paulo, 2012.

GADOTTI, M. Extensão universitária: para quê. São Paulo: Instituto Paulo Freire, 2017.

MOIMAZ, S. A. S. et al. Extensão universitária como ferramenta geradora de ensino-aprendizagem e produtora de pesquisa. Revista Conexão, Ponta Grossa, v. 11, n. 2, p. 140-149, maio/ago. 2015.

PEREIRA, S. M. Extensão universitária e trabalho voluntário na formação do acadêmico em Odontologia. Arquivos em Odontologia, Belo Horizonte, v. 47, n. 2, p. 95-103, abr./jun. 2011.

PIVETTA, H. M. F. et al. Ensino, pesquisa e extensão universitária: em busca de uma integração efetiva. Linhas Críticas, Brasília, v. 16, n. 31, p. 377-390, jul./dez. 2010.

STROMBERG, A. et al. A contribuição das ações extensionistas do Projeto Rondon na formação do estudante de Odontologia. Revista Conexão, Ponta Grossa, n. 16, p. 1-12, 2020.

ZANON, D. P.; ALTHAUS, M. T. M.; BAGIO, V. A. Didática na docência universitária em saúde: metodologias ativas e avaliação. Curitiba: Appris, 2018.

Recebido em: 30/09/2020

Aceito em: $13 / 08 / 2021$ 